\title{
A SUBJETIVIDADE DE ENFERMEIROS EXPRESSANDO EM ARTE O SIGNIFICADO DO CUIDADO À FAMÍLIA ${ }^{1}$
}

\author{
Emanuelle Caires Dias Araújo Nunes², Luzia Wilma Santana da Silva
}

\footnotetext{
${ }^{1}$ Recorte da dissertação - Cuidar integralmente o sistema familiar: o desafio da transpessoalidade para a práxis de enfermagem, apresentada ao Programa de Pós-Graduação em Enfermagem e Saúde (PPGES) da Universidade Estadual do Sudoeste da Bahia (UESB), 2010.

${ }^{2}$ Mestre em Enfermagem e Saúde. Professora Assistente da Universidade Federal da Bahia. Bolsista CAPES. Bahia, Brasil. E-mail: manoharaujo@ig.com.br

${ }^{3}$ Doutora em Enfermagem. Professora Adjunto do Departamento de Saúde UESB e docente do PPGES/UESB. Bahia, Brasil. E-mail: luziawilma@yahoo.com.br
}

RESUMO: Trata-se de um estudo descritivo de abordagem qualitativa que objetivou compreender o significado do cuidado ao indivíduofamília expresso por enfermeiros na Estratégia de Saúde da Família. A coleta de dados envolveu nove sujeitos que elaboraram um desenho acerca do significado do cuidado ao sujeito-família, seguido de descrição verbal gravada. A análise pautou-se na técnica temadesenho-texto. Os resultados apontaram para três eixos temáticos: cuidado contextualizado, cuidado vincular e cuidado intersubjetivo expressos por imagens e palavras que revelaram singularidades subjetivas da compreensão de cuidado, expressando a interioridade vivencial dos enfermeiro. Conclui-se que o significado do cuidar perpassa pelo vínculo intersubjetivo, essencial para o desenvolvimento de um cuidado transpessoal ao sistema familiar. Para tanto, é necessário acessar a subjetividade dos enfermeiros, estimulando um processo de autoconhecimento e envolvimento com os sujeitos-famílias com os quais estes interagem.

DESCRITORES: Enfermagem. Família. Cuidado. Arte.

\section{NURSE SUBJECTIVITY EXPRESSING THE SIGNIFICANCE OF FAMILY CARE THROUGH ART}

\begin{abstract}
This is a descriptive study of qualitative approach that aimed to understand the meanings of care provided to the individual-family as expressed by Family Health Strategy nurses in Brazil. Data was collected involving nine subjects who produced a drawing attributing the meaning of care for the individual-family, followed by recorded verbal descriptions. Data analysis was based on the theme-design-text technique. Results showed three themes: contextualized care, bound care, and inter-subjective care, expressed by images and words that showed subjective singularities of understanding care, expressing nurses' existential interiority. We conclude that the meaning of caring permeates the inter-subjective bond, which is essential to develop transpersonal care for the family system. Therefore, it is necessary to access the nurses' subjectivity by encouraging a self-awareness process and involvement with the subjects-families with whom they interact.
\end{abstract}

DESCRIPTORS: Nursing. Family. Care. Art.

\section{LA SUBJETIVIDAD DE LOS ENFERMEROS: EL SIGNIFICADO DEL CUIDADO A LA FAMILIA EXPRESADO A TRAVÉS DEL ARTE}

\begin{abstract}
RESUMEN: Se trata de un estudio descriptivo con enfoque cualitativo para comprender el significado de la atención al individuo-familia expresado por enfermeros en la Estrategia de Salud Familiar. La recolección de datos incluyó nueve sujetos que hicieron un dibujo sobre el significado del cuidado a la familia, seguido por una descripción verbal grabada. El análisis se basó en la técnica: tema-diseño-texto. Los resultados mostraron tres ejes temáticos: el cuidado contextualizado; el vínculo del cuidado y el cuidado intersubjetivo, expresados a través de imágenes y palabras que revelan singularidades subjetivas de la comprensión del cuidado, expresión de la interioridad existencial de los enfermeros. Se concluye que el significado de cuidar permea el vínculo intersubjetivo, esencial para el desarrollo del cuidado transpersonal de un sistema familiar. Por lo tanto, es necesario acceder a la subjetividad de los enfermeros, fomentando un proceso de autoconocimiento y la participación con los sujetos y las familias con las que interactúan.
\end{abstract}

DESCRIPTORES: Enfermería. Familia. Cuidado. Arte. 


\section{INTRODUÇÃO}

A subjetividade é definida como o que é pessoal, individual, referente à interioridade, aquilo que pertence ao sujeito cognoscente, sua sensibilidade. ${ }^{1}$ Essa definição é adotada neste estudo pela compreensão do indivíduo como um ser de sensibilidade para o cuidado contextual familiar.

Emerge assim, a necessidade de ampliar a abordagem de cuidados aos aspectos subjetivos da família, buscando subsidiar um cuidado integral no ambiente da Estratégia de Saúde da Família (ESF), capaz de alcançar o sistema familiar em sua multidimensionalidade e complexidade de ser e existir, visto que essa Estratégia, embora devesse alcançar a família em sua globalidade, ainda trabalha de forma a fragmentar os membros da família em programas instituídos de forma verticalizada, quando, na nossa compreensão, tal estratégia deveria alcançar a família em seu ambiente de relações, ou seja, o lar, cenário de suas vivencias, experiências, valores e sentimento de pertença.

Para este caminhar de reflexão-ação de cuidados, elegeu-se como fundamentação a Teoria do Cuidado Transpessoal, ${ }^{2}$ por sua abordagem de valorização ao corpo-mente-alma de cada sujeito, em sua inteireza, e da família, em sua globalidade.

A apreensão deste ser subjetivo e inter-relacional ampara-se ainda no pensamento sistêmico, por compreender a família como sistema aberto de influência mútua entre indivíduos numa teia relacional recursiva de cuidados, e, para tanto, a serem assistidos pela Estratégia de Saúde da família na sua integralidade.

Frente a isto, acreditamos residir na subjetividade, a 'semente' que faz germinar a integralidade para o alcance da saúde da família. A integralidade se faz como prática intersubjetiva, princípio que enlaça os demais enunciados pelo Sistema Único de Saúde (SUS), significa levar em conta os modos de "andar a vida" dos sujeitos-família do cuidar em saúde, ${ }^{3}$ e olhar para a profissão enfermagem, aquela que se encontra entre as profissões de saúde mais próxima ao sistema familiar, implica na busca do construir, a partir do diálogo, projetos terapêuticos relacionais circulares, ou seja, que considerem trocas com os indivíduos em sua subjetividade e interações humanas a partir das relações familiares comunicacionais. ${ }^{4}$ Assim, estar mais próximo da família, em seu domicílio, como enfermeiros de família.

A família passa a ser uma unidade essencial de cuidado numa compreensão novo-paradigmática, onde sua organização não se dá de forma estática, mas globalizante, dinâmica, conceitual e complexa, em interação com o meio, o que a define como sistema. Neste espaço, busca-se o "equilíbrio", em face às constantes mudanças que orientam para sua sustentabilidade. Sob a ótica desta abordagem, a família configura-se como um conjunto articulado de seres humanos de singularidades, influenciando o todo e as partes, e sofrendo influência deste, numa inter-relação contínua, responsável pela construção do "sistema familiar", de seus valores sociais, ético-morais e conceituais de saberes e saúde. ${ }^{5}$

Dessa forma, surge um novo significado para as práticas em saúde, a partir de um olhar que propõe a compreensão da complexidade das relações, das trocas e do próprio processo de cuidar em saúde, o que não pode ser apreendido como algo pronto, estático e/ou como um fim em si mesmo, pois se caracteriza como dinâmico e interativo; fenômeno que demanda um processo dialógico-reflexivo por parte dos profissionais da saúde, usuários, instituições e pesquisadores. ${ }^{6}$

Entretanto, a intersubjetividade perpassa por uma dimensão na qual os profissionais precisam aguçar seus conhecimentos para identificar as necessidades de bem-estar de cada sujeito e cada família com que se relacionam, não reduzindo-lhes à doença quelhes provoca sofrimento, numa visão reducionista. Essa abordagem encontra diversas dificuldades de aderência no contexto de práticas de saúde. Os enfermeiros admitem a necessidade de uma assistência mais proximal-emocional, entretanto, apontam diversos entraves para seu cumprimento de natureza administrativa, falta de experiência, despreparo acadêmico, medo de envolver-se e insegurança.?

A busca por estudos acerca desta temática, nas bases de dados, demonstrou uma lacuna no conhecimento, pois poucos estudos se mostram perspectivados para delinear a subjetividade na relação de cuidado de enfermeiros às famílias, em nível primário, mostrando-se um campo que precisa ser percebido, assumido e lapidado para uma maior aproximação à práxis da integralidade. Acreditamos que, ao explorar o autoconhecimento e percepção do enfermeiro, acerca do cuidado às famílias, encontraremos subsídios à aproximação de cuidados relacionais, inquietação que fez emergir um trabalho de dissertação de mestrado sobre esta temática na busca pela compreensão do saber do enfermeiro sobre o seu cuidado à família a partir de sua subjetividade, de modo que traçamos como objetivo compreender o significado do cuidado ao indivíduo-família, expresso pela(o) enfermeira(o), na ESF. 


\section{METODOLOGIA}

Trata-se de um estudo descritivo com abordagem qualitativa, cujo cenário de pesquisa abrangeu Unidades de Saúde da Família do município de Vitória da Conquista, Bahia. Os sujeitos deste estudo foram nove enfermeiros selecionados por meio de amostragem não-probabilística delimitada pela saturação dos dados. O critério de inclusão foi estarem atuando na ESF há pelo menos três anos, o que, à luz da nossa compreensão, possibilitaria a expressão de suas vivências e experiências. A pesquisa seguiu a Resolução 196/96, aprovada sob protocolo no 185/2009, do Comitê de Ética e Pesquisa da Universidade Estadual doSudoeste da Bahia. Os dados foram coletados após assinatura do Termo de Consentimento Livre e Esclarecido, no período de janeiro de 2010.

Como técnica de coleta de dados foi utilizado o desenho, sendo disponibilizado papel canson profissional ${ }^{\circledR} 200 \mathrm{~g} / \mathrm{m}^{2} \mathrm{~A}_{4}$ branco, hidrocores na cor preta, caixa de lápis de cor com 12 cores, borracha, apontador, lápis grafite $9 \mathrm{~B}$ e lápis grafite 6B. A técnica consistiu na elaboração de um desenho como expressão artística do ser enfermeiro. Foi realizado em ambiente privativo na Unidade de Saúde da Família. O desenho foi guiado pela pergunta: como pode retratar o significado do cuidado ao sujeito-família? Essa estratégia teve duração média de 20 minutos. Após expressão artística, o desenho, o sujeito da pesquisa foi convidado a falar sobre sua arte, a descrição foi gravada para análise compreensiva do desenho, sendo-lhe solicitado ainda que formulasse um título para sua obra.

Durante a expressão artística foi observado nos sujeitos comportamentos que os remetia ao ser criança, ao manuseio com o lápis de cor e o papel, no processo do desenhar. Tal observação validava-se com expressões verbais como: "voltei a ser criança"; "gosto tanto de desenhar"; e não-verbais: sorrisos desconfiados; aumento de movimentos gestuais - inquietudes, olhar atento e estado de relaxamento, sensações que os possibilitaram transmitir para o papel o significado do cuidado, fala expressa pelos participantes.

A análise pautou-se na compreensão do desenho - objeto de expressão artística do ser, como unidade de significado à compreensão de estudos qualitativos. O desenho, nesta perspectiva, possui significado para conhecer a realidade estudada. Para tanto, é ancorado pelo texto que o acompanha e pelo status atribuído pelo sujeito, a expressão artística revela um sistema de signos o qual necessita da mediação da linguagem, que extrai seus signifi- cantes e nomeiam seus significados. ${ }^{8}$ A expressão artística do ser - o desenho, criação dos sujeitos do estudo - realça a compreensão entre linguagem e imagens. Ao estar acompanhada de um texto, esta imagem, sempre polissêmica, exclui a ambiguidade inerente à sua interpretação, surgindo como elemento de expressão lúdica que expressa modelos cognitivos-subjetivos, de maneira a enriquecer o sentido completo do significado atribuído ao cuidado pelos enfermeiros em estudo.

\section{RESULTADOS E DISCUSSÃO}

Os resultados foram organizados em consonância à proposta analítica tema-desenho-texto. A análise das expressões (imagens e palavras) revelaram diferentes nuances e perceptivas, dada a subjetividade inerente à vivência compreensiva dos enfermeiros, entretanto, sentimentos comuns corroboraram para a organização em três eixos temáticos: cuidado contextualizado, cuidado vincular e cuidado intersubjetivo. A apresentação dos resultados inicia com as falas e desenhos que expressam os eixos temáticos, para em seguida explorar esses resultados e discuti-los com a literatura.

\section{Cuidado contextualizado}

\section{A saúde no contexto da família}

[...] a gente tem que ver o todo [...] em que contexto está essa família, se é uma família bem estruturada, se existe um vínculo afetivo entre eles [...] não vejo o indivíduo sozinho como o corpo dele [...] tem que ter um olhar ampliado, não só em relação à patologia, mas todos os fatores que influenciam no bem estar do indivíduo. $O$ sol, as nuvens, o coração são porque eu gosto de trabalhar nisso, para mim quando eu desempenho a função como enfermeira do Programa de Saúde da Família não é um trabalho, eu faço com amor [...] (Assistência).

\section{Família assistida, família saudável e feliz}

Bom, aqui eu desenhei, eu fiz assim: a família, pai, mãe e uma criança [...] próximo deles tem a Unidade de Saúde da Família [...] eles usam água tratada, com caixinha com tampa, sistema de esgoto [...] casa bem arejada [...] tá tudo tranquilo (Confiança).

\section{A interação do cuidado com o contexto familiar}

[...] sempre uma história está interligada a outra, e, a gente nunca dá para pensar o indivíduo sozinho, ele tá inserido no seu contexto [...] (Sensibilidade). 


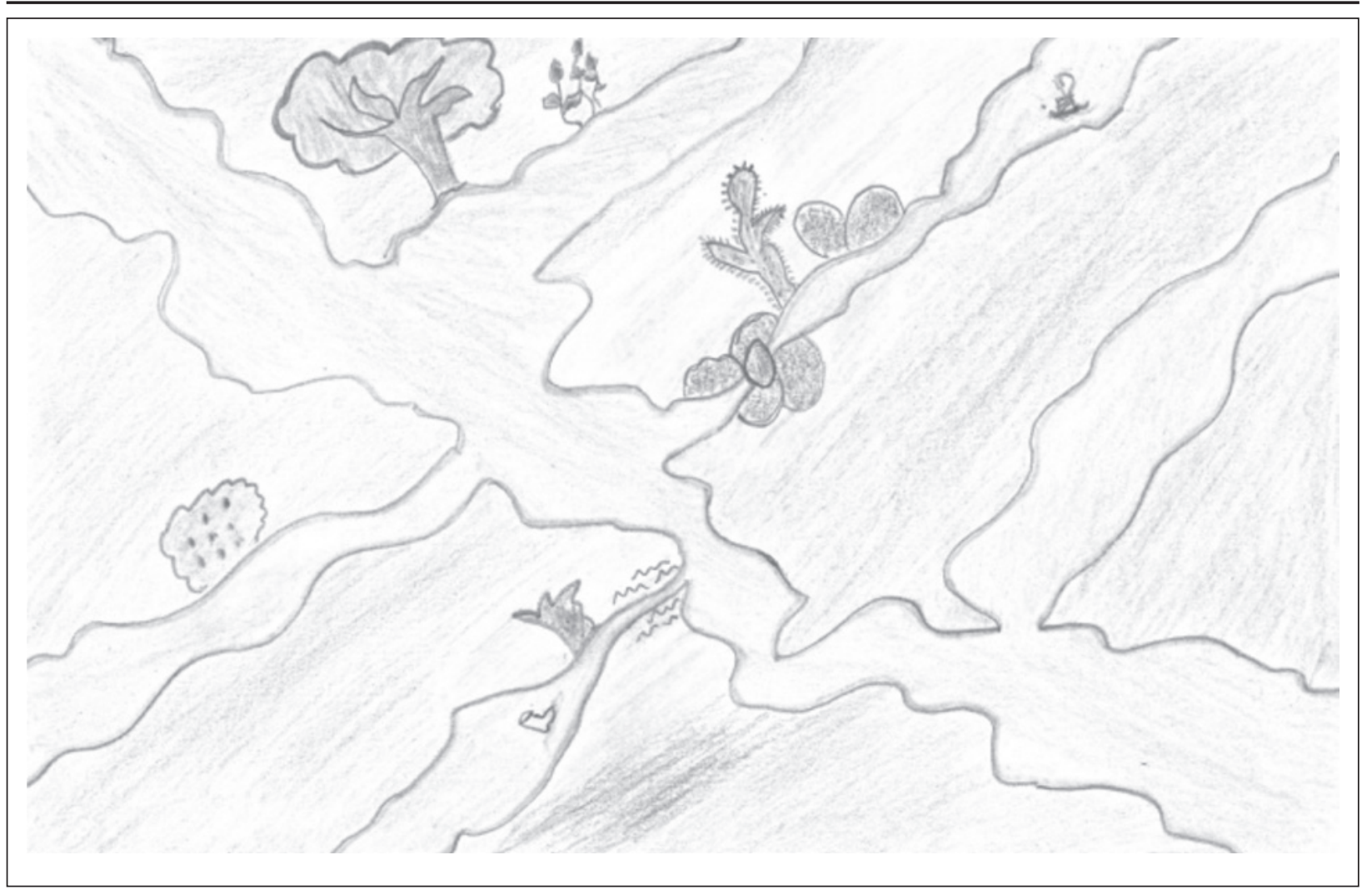

Figura 1 - Continuidade

[...] é um desafio constante. Está sempre em movimento essa questão do cuidado ao indivíduo-família, até porque, não são seres dissociados, separados. O indivíduo, ele vive em contexto [...] e por conta disto se sofre a influência direta ou indiretamente dessas pessoas. [...] tentei retratar neste desenho [...] um rio [...] que tem o seu curso e está sempre em movimento. [...] Às vezes tudo azul [...], com flores, com árvores saudáveis. Bem, mas com seus desafios também, coisas positivas e coisas negativas [...]. Este afluente teve um fluxo maior e por conta de problemas, tá com fluxo menor, reduzido por conta de dificuldades [...] sofre mudanças ou influências, mas como o curso do rio deve seguir em frente e, a depender da situação, deve-se tentar definir melhor estratégias [...] a gente também deve continuar tentando e continuar seguindo pra tentar melhorar a qualidade de vida das pessoas e a atuação enquanto a Equipe de Saúde da Família. Não é fácil, não! [...] mas, vai ser um desafio constante [...] o melhor de tudo é que mantém sempre o curso e a gente sempre tem possibilidade de estar tentando, apesar da seca, apesar das queimadas, apesar da poluição [...] partes um pouco áridas com rochedos [...]. Com as dificuldades a gente também tem que se adaptar e crescer [...] (Esperança).

As expressões delineiam uma percepção dos enfermeiros que valoriza e descreve um cuidado contextualizado (primeiro eixo). Confluem para a importância de integrar o indivíduo-família em seu universo de valores e vivências, meio responsável pelo seu processo de cuidado e saúde. Neste entendimento, a família foi enunciada como um todo organizado em interação dinâmica entre si (partes) e com o contexto (meio). Inter-relações que, percebidas pelos enfermeiros, desvelam para eles a necessidade de abordarem este universo de cuidados de maneira diferenciada. Demonstram que sua experiência aponta para a necessidade de enxergar o todo onde se insere o sujeito-família.

Essa ótica de cuidado encontra respaldo no Pensamento Sistêmico que, ao compreender a família como um sistema, não avalia prioritariamente o sintoma do sujeito doente, mas sim o que faz ocasioná-lo e as relações que o mantém. A doença deixa de ser considerada consequência de um individual perturbado, figurando o que fluiu no interior da 'célula' familiar e social a partir das relações. Muitas vezes, somente uma pessoa apresenta sintoma de desvio de saúde, entretanto, é preciso considerar, nessa visão, que o indivíduo acometido pode ser somente o "bode expiratório" da família, o que demonstra à sociedade os problemas envolvidos nessa interação. ${ }^{9}$

Emerge assim a importância do processo transpessoal de cuidado que valoriza o convívio 
intersubjetivo entre enfermeiro e família, mantendo vivo o senso comum de humanidade por meio da identificação de si no outro, através da qual cada um se descobre e manifesta seu humanismo no reflexo do outro, conferindo à enfermagem a função de cuidar da totalidade e inteireza da personalidade humana ${ }^{2}$.

Esta interação vivenciada pelos sujeitos faz compreender que o ato de cuidar requer o interesse pela transpessoalidade e complexidade que abrange sujeito-família-sociedade. A fala de Esperança expressa mais significativamente as vicissitudes que permeiam a atuação da enfermagem. Enlaça conflitos e enfrentamentos que permeiam o ir e vir pelos caminhos do cuidado no âmbito da ESF. Revela sensibilidade e envolvimento do ser enfermeiro no cotidiano que reserva sempre dualidades, erros e acertos, tristezas e alegrias e acima de tudo o desafio de participar ativamente deste fluir pelo 'rio' de aventuras e cuidado genuíno.

Alcançar as necessidades sublimadas de cuidado demanda, assim, assumir este constante desafio de construção do cuidado ao sistema-família, por meio de uma práxis de enfermagem capaz de transcender além do cunho técnico, à ação responsável pelo crescimento de quem é cuidado e de quem cuida. Portanto, o cuidado à família em sua complexidade constitui-se numa questão ainda a ser aperfeiçoada no cotidiano do cuidar, embora os profissionais sujeitos deste estudo já aludam em suas falas expressões desta forma de cuidar.

Essa interação precisa ser efetiva, resgatando o cuidado que visa a preencher a lacuna da necessidade humana ampliada, considerando não somente os momentos de doença, mas o ser em sua totalidade, sua história, origem, identidade, inserção, ambientação. Assistir requer, portanto, o interesse pela complexidade que abrange sujeito-família-sociedade, seguido de acolhimento e empreendimento de estratégias capazes de melhorar a realidade das famílias.

Deste modo, as ações em saúde, pensadas com base na família, buscam ter o intuito de conhecer o que ela sabe e pratica em relação ao cuidado de seus membros. Este exercício de ir e vir na família, considerando-a como sujeito do cuidado de saúde, é um desafio para os profissionais, uma vez que esta abordagem contextualizada exige uma formação profissional diferenciada, a qual ainda permanece sendo um desafio a ser consolidado. ${ }^{10}$

Nesse sentido, destaca-se a importância de valorizar os indivíduos e sua autoestima para que estes possam mobilizar-se a partir de uma formação mais crítico-reflexiva direcionada para a integrali- zação do sujeito em seu contexto, valores e história de vida. Dessa forma, propõe-se o diálogo como a chave que os profissionais de saúde precisam ter para "abrir as portas" da qualidade de cuidados às populações, através de círculos de cultura, de discussão de unidades de conteúdo, configurando um aprendizado mútuo, bidirecional e horizontal. ${ }^{11}$

\section{Cuidado vincular}

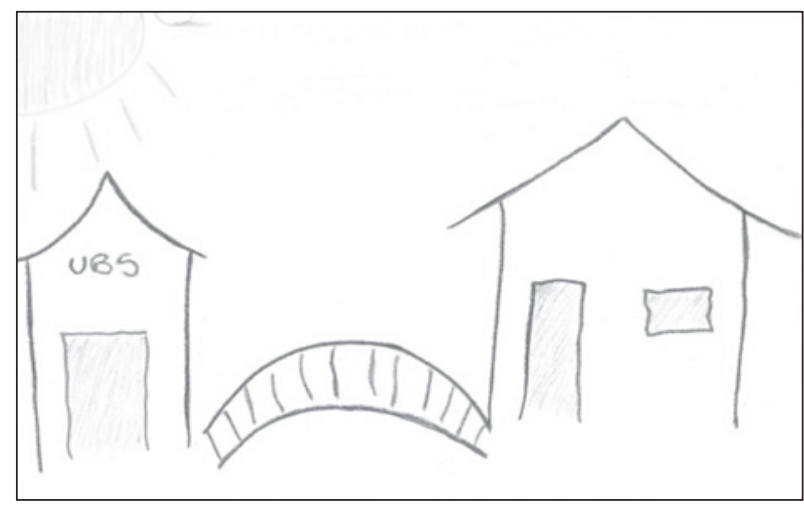

Figura 2 - A ponte do cuidado

Ó, eu coloquei a casa que pra mim é o que representa a família, o lugar onde ela vive [...]. Do outro lado, a Unidade Básica de Saúde, que é quem vai prestar esses cuidados. No meio, não ficou bonitinha, mas é uma ponte. Então pra mim o cuidar é você estabelecer um vínculo e essa ponte aqui representa esse vínculo, porque só quando eu conheço, quando eu visito, quando eu converso, escuto é que eu vou saber o que é a vida dessa pessoa, o que representa pra ela, pra família dela [...] essa família, essa pessoa, essa comunidade, tendo essa ponte de ligação, tendo esse vínculo, ela vai poder nos ajudar a cuidar tanto da própria unidade [...] então é uma troca. A ponte aqui significa o vinculo, a troca, o conhecimento, $o$ carinho, porque sem carinho não existe cuidado [...] sem esse vínculo você não consegue nada (Conforto).

\section{Tudo vale a pena se a alma não for pequena}

[...] eu desenhei umas florzinhas, cada uma de uma cor, porque cada uma é pessoa e tem seus [pausa de voz] valores, princípios. [...] como família, como equipe [...] está no contexto, e tem que ser trabalhando junto e em grupo, cada um com a sua personalidade para poder se trabalhar, porque família tem que ser trabalhada assim, entendendo a particularidade da pessoa, entendendo o que tá acontecendo. O cuidado é atenção, é ouvir o paciente. Primeiro cuidado de tudo que eu entendo é o ouvir, depois que eu escuto o paciente, aí sim eu vou saber qual o cuidado [...] (Solidariedade).

As expressões acima assimilam a ligação entre sujeitos-família e profissionais de saúde. 
Seja como ponte do cuidado, de maneira concreta: existência de uma ponte, ou com a citação "Tudo vale a pena se a alma não for pequena", de maneira subjetiva: existência de afetividade, os enfermeiros ressaltam a importância do vínculo para a efetividade do cuidado. A interação unidade-família e equipe-família, respectivamente, se mostram como o principal valor a ser cultivado, preservado pelos cuidadores de famílias.

Por isso, a compreensão do cuidado amplo designa aquele que inclui o sentimento e a família no seu processo, o que requer do profissional doar-se mais completamente para conversar e conhecer as experiências do paciente, abrangendo importantes dimensões subjetivas do cuidado: tocar, conversar, apoiar, informar, fazer companhia ou simplesmente ficar com o paciente, oferecendo-lhe sua presença, ${ }^{12}$ atitudes que expressam o cuidado transpessoal, referencia teórica deste estudo.

O vínculo é grande facilitador do cuidado, pois confere a relação, a confiança e o desvelo necessários à práxis transformadora e mobilizadora das capacidades do sujeito no intuito de promover e manter sua saúde, entendida como o conjunto de forças físicas, afetivas, psíquicas e sociais que podem ser ativadas para compensar a doença. ${ }^{13}$

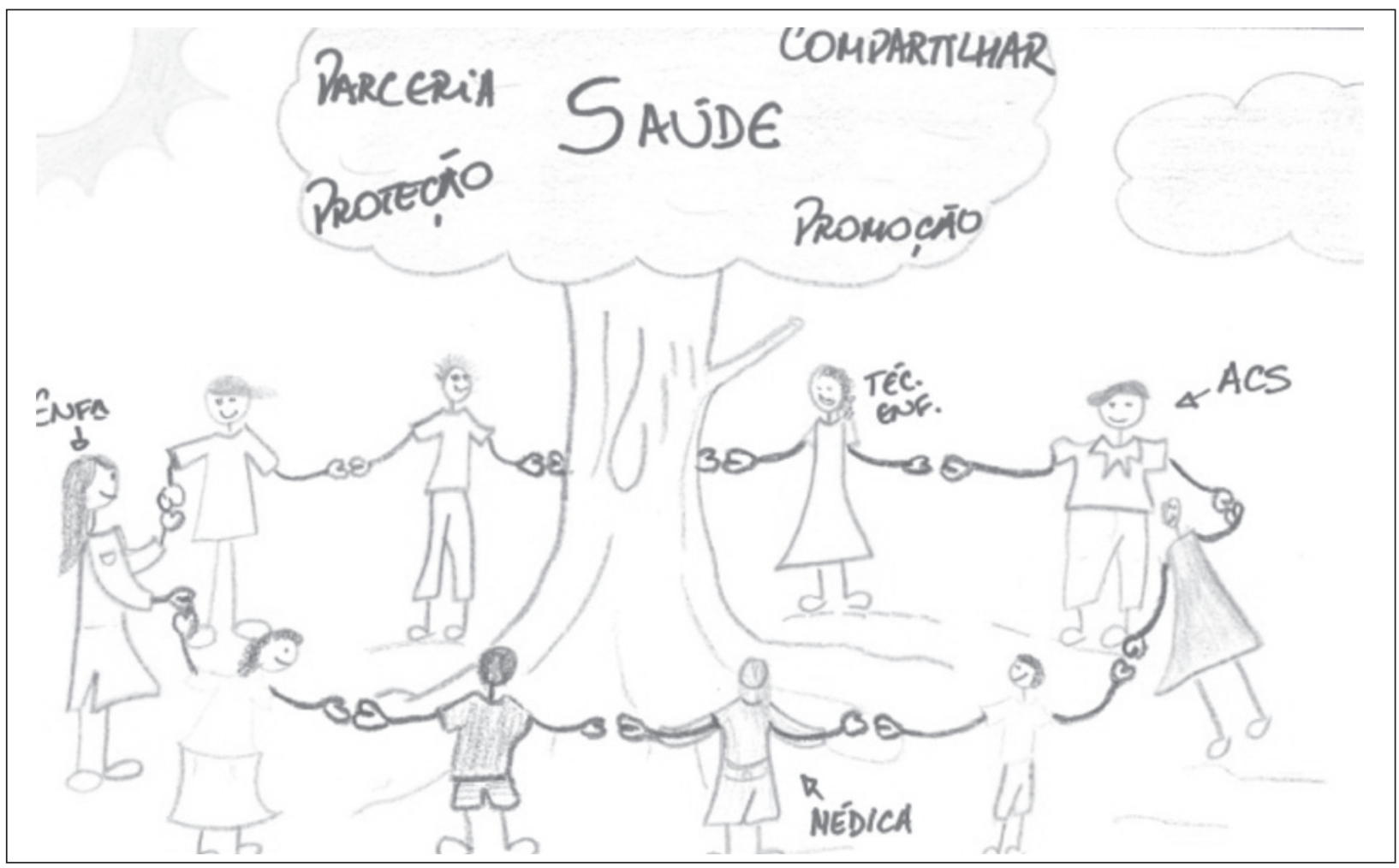

Figura 3 - A arte do cuidado

\section{Cuidado intersubjetivo}

Ficou bonitinho [risos]! Bom, o desenho significa um abraço fraterno entre a comunidade es profissionais de saúde. Cada um representando o seu papel profissional; mas a gente tá no mesmo patamar, a gente tá no mesmo círculo [...] e a gente tá de mão dada pra estar passando ajuda, um auxilia o outro, a gente auxilia a comunidade, a comunidade auxilia a gente, com conhecimento, com prática, com vivência, com história [...]. A árvore no meio, é saúde, promoção à saúde, proteção à saúde, parceria coletiva e compartilhamento de saberes [pausa de voz]. Ah! O sol e a nuvem [...] deu mais claridade ao desenho, deu mais vida, porque o sol tá brilhando, o dia tá alegre, então é otimismo [risos] (Conhecimento).

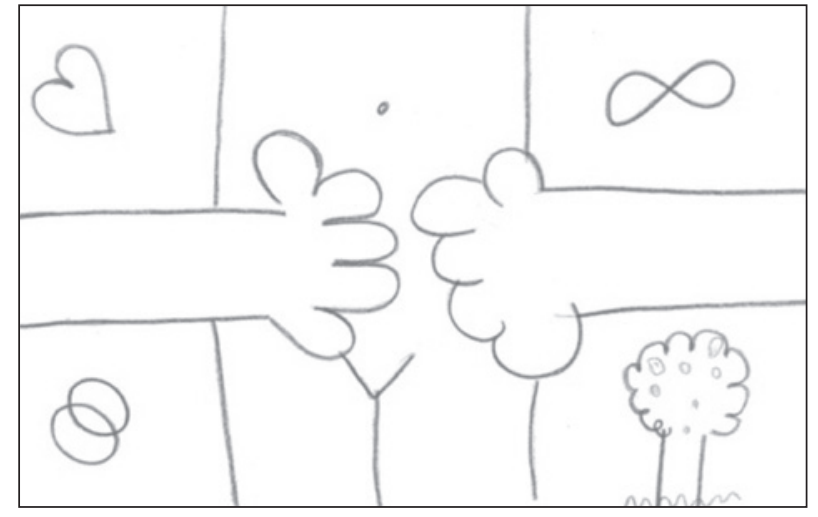

Figura 4 - Todos nós 
[...] desenhei um abraço, porque o cuidado é realmente você abraçar o outro e tentar entender suas necessidades, quando você abraça você também se entrega ao outro, você envolve seu corpo [...] coloquei o abraço nesse sentido de você se envolver no todo dele. Coloquei aqui um coraçãozinho representando o amor pelo outro. Duas alianças como se fosse o elo do profissional com o paciente. O símbolo do infinito [...] porque sempre o indivíduo vai está retornando, ele sempre vai ter uma demanda pra você dá conta [...], uma arvorezinha com os frutos que é o resultado (Amor).

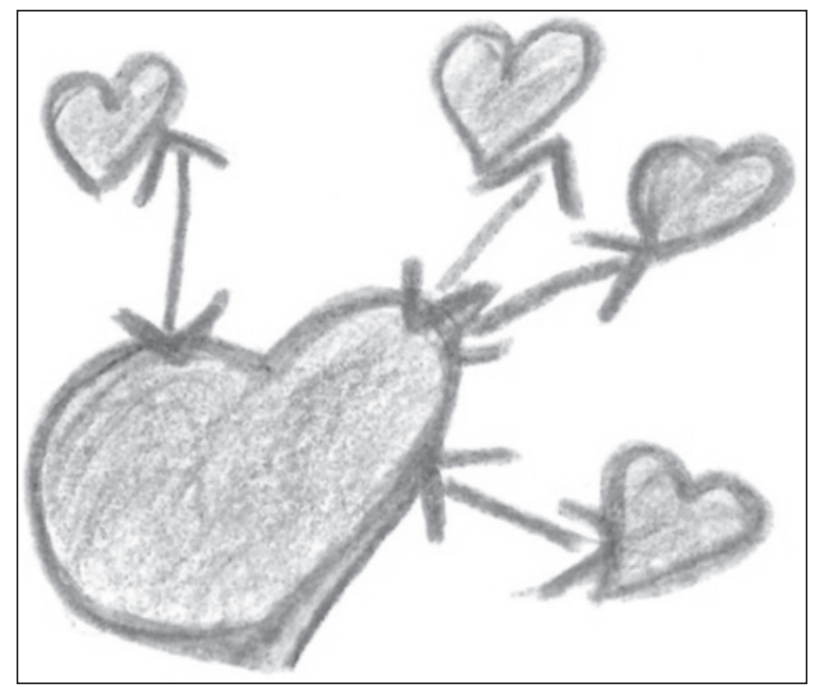

Figura 5 - Cuidando e sendo cuidado

O cuidado para mim representa o amor, o amor que você tem ao que você faz, a forma que você se propõe a fazer, porque este é o diferencial no cuidado, porque cuidar por cuidar parece até, é simples, o cuidar com amor, com empatia é bem diferente [...] requer da gente mais um pouco de esforço [...]. Eu representei aqui com esse coraçãozinho [...] e na verdade aqui eu posso fazer outros, porque a gente não vive sozinho. A gente tem que cuidar e ser cuidada [...] a gente não tem nem oportunidade às vezes de manifestar o que tá sentindo [...]. Você cuida, cuida, cuida, cuida, tá todo mundo aqui atendido, maravilhoso, e você [...] acho que tem que ser assim, uma mão dupla, que vem e que vai (Aprendizagem).

As expressões deste último eixo consolidam e completam os dois anteriores ao trazerem à discussão uma práxis intersubjetiva no cuidado de enfermagem à família. Esta implica na troca de experiências, conhecimentos e afetividades que poderá se estabelecer entre cuidador e ser cuidado ao se doarem num abraço de envolvimento mútuo, conforme referido em Todos nós e confirmado nas mãos dadas de A arte do cuidado.
Essa intersubjetividade envolve sentimento de amor e consideração que desencadeia em cada ser multidimensional a transpessoalidade no cuidar reciprocamente demonstrando sua importância e valor na rede vincular.

Portanto, o cuidado de enfermagem requer compromisso ético, moral e estético fomentadores da postura profissional para o alcance da compreensão do cuidado, enquanto essência da integralidade do ser que está sendo cuidado, de modo que sua ação contemple a pessoa humana nos aspectos biopsicológico, emocional, social, cultural e ecológico. Para tanto, o cuidador enfermeiro adota uma postura que compreenda o crescimento e o desenvolvimento deste cuidado, ${ }^{14}$ de forma a ampliar seu olhar na perspectiva de enxergar o ser que está sendo cuidado intersubjetivamente.

A abordagem humanística aponta como base de cuidados o encontro entre o ser que cuida e o ser que é cuidado numa esfera transpessoal, na qual se pretende alcançar uma harmonia entre corpo-mente-espírito a partir das trocas entre eles. Nessa perspectiva, é possível assimilar a analogia do cuidado com o espelho. Assim como o espelho gera uma reflexão daquilo que é apreendido por ele, o cuidado que habita cada ser reflete ações compatíveis com a dimensão que este ocupa. Portanto, a atitude humana e profissional frente ao mundo comunica o cuidado pessoal, ou seja, a essência de cada um, o reflexo das experiências vividas ao longo da vida e a capacidade de transmitir e compartilhar coisas boas e nobres conquistadas numa relação de envolvimento e maturidade que evoca a solidariedade humana. ${ }^{12}$

Desta forma, busca-se um cuidar que resgate o humano, o solidário, o sensível, o crítico-reflexivo, o saber científico-popular, o cultural-ecológico, numa reciprocidade e crescimento mútuo entre profissional e sujeitos-cidadãos de sua práxis. Um fenômeno vital, dinâmico e essencial no sistema de cuidados à saúde.

\section{CONSIDERAÇÕES FINAIS}

A capacidade de cuidar está relacionada a quanto e como o ser foi cuidado, como o cuidado é percebido, sentido, internalizado por ele. Este cuidado consiste no corpo de conhecimento fundamentado no cuidar-essência da profissão Enfermagem, o que se revestena responsabilização a partir do envolvimento e comprometimento profissional com o individual e coletivo, concebendo o princípio moral e (re) significando no seu cotidiano na práxis de cuidar. 
O vínculo intersubjetivo emergiu no estudo como essencial para o desenvolvimento de um cuidado transpessoal ao sistema familiar. Nesta perspectiva, a transpessoalidade confluiu numa compreensão de entrelaçamento com a subjetividade humana revelada na interação expressa em arte pelos enfermeiros, demonstrando a importância da busca por um processo de autoconhecimento destes profissionais cuidadores desvelado no envolvimento com os sujeitos-famílias com os quais interage.

A formação profissional humanística de enfermagem também possui importante influência na práxis de cuidados que o enfermeiro consegue assumir, todavia, não se restringe à ela a responsabilidade de facilitar este processo interativo/ educativo na construção da saúde das famílias, pois a transpessoalidade se conquista com autoconhecimento, envolvimento e determinação em doar-se ao cuidado, admitindo-se como parte deste e não somente como seu executor.

Neste sentido, nós enfermeiros somos, como 'galinhas' (presas ao solo) enquanto seres concretos, históricos e que coabitam um universo de dificuldades, mas não devemos nos esquecer de evocar a nossa 'águia' (livre ao voar), paixão indomável, projeto infinito de busca por melhorias e novas possibilidades. ${ }^{15}$ Conciliemos as dimensões (galinha-águia) neste discurso-ação de totalidade, enraizados na realidade, mas abertos ao possível ainda não ensaiado. Busca que não prima pelo perfeito e total, mas pela aproximação contínua, por meio de novas descobertas, novos alvos e ideais, que impulsionem à crescente qualidade do cuidado à família.

\section{REFERÊNCIAS}

1. Japiassú H, Marcondes D. Dicionário básico de filosofia. $3^{\mathrm{a}}$ ed. Rio de Janeiro: Jorge Zahar Ed; 1996.

2. Watson J. Enfermagem: ciência humana e cuidar uma teoria de enfermagem. Loures (PT): Lusociência; 2002.

3. Mattos RA. A integralidade na prática (ou sobre a prática da integralidade). Cad Saúde Pública [online]. 2004 [acesso 2009 Abr 09]; 20(5). Disponível em: http://www.scielo.br/scielo.php?script=sci_

Correspondência: Emanuelle Caires Dias Araújo Nunes

Rua São Pedro, 264

45015-200 - Centro, Vitória da Conquista, BA, Brasil

E-mail: manoharaujo@ig.com.br arttext\&pid=s0102-311 $\times 2004000500037 \& \operatorname{lng}=$ pt\& nrm=iso.

4. Watzlawick P, Beavin HB, Jackson D. Pragmática da comunicação humana - um estudo dos padrões patologias e paradoxos da interação. São Paulo: Cutrix, 1967.

5. Silva LWS, Gonçalves LHT, Costa MASMC. Abordagem sistêmica de enfermagem à família considerações reflexivas. SERVIR. 2006 Set-Out; 54(5):214-23.

6. Erdmann AL, Souza FGM, Backes DS, Mello ALSF. Construindo um modelo de sistema de cuidados. Acta Paul Enferm [online]. 2007 [acesso 2009 Abr 07]; 20(2). Disponível em: http://www.scielo. br/scielo.php?script=sci_arttext\&pid=s010321002007000200011\&lng=en\&nrm=iso.

7. Scherer ZAP, Scherer EA, Labate RC. Interconsulta em enfermagem psiquiátrica: qual a compreensão do enfermeiro sobre esta atividade?. Rev Latino-am Enfermagem. 2002 Jan; 10(1):7-14.

8. Penn G. Análise semiótica de imagens paradas. In: Bauer MW, Gaskell G. Pesquisa qualitativa com texto, imagem e som. $7^{\text {a }}$ ed. Petrópolis (RJ): Vozes, 2008. p.319-42.

9. Milani DS, Rodrigues DB, Vicente RB. A importância da família e suas relações: um estudo de caso. Psicol Argum. [online]. 2006 [acesso 2009 Jul 16]; 24(47). Disponível em: http:/ / www2.pucpr.br/reol/index. $\mathrm{php} / \mathrm{pa}$.

10. Resta DG, Motta MG. C. Família em situação de risco e sua inserção no programa de saúde da família: uma reflexão necessária à prática profissional. Texto Contexto Enferm. 2005; 14(Esp):109-15.

11. Freire P. Educação como prática da liberdade. Rio de Janeiro (RJ): Paz e Terra, 2000.

12. Waldow VR. O cuidado na saúde: as relações entre eu, o outro e o cosmos, Petrópolis (RJ): Vozes, 2004.

13. Collière M. Promover a vida, da prática das mulheres de virtude aos cuidados de enfermagem. Lisboa (PT): Lidel - edições técnicas e sindicato dos enfermeiros portugueses; 1999.

14. Marcon SS, Elsen I. A enfermagem com um novo olhar... a necessidade de enxergar a família. Fam Saúde Desenv [online]. 1999 [acesso 2008 Jul 11]; 1(1.2). Disponível em: Disponível em: http://ojs. c3sl.ufpr.br/ojs2/index.php/refased/article/ viewpdfinterstitial/4877/3727.

15. Boff L. A àguia e a galinha: uma metáfora da condição humana. Petrópolis (RJ): Vozes; 1997. 